\title{
High-fat diet exposure from pre-pubertal age induces polycystic ovary syndrome (PCOS) in rats
}

\author{
Roshni Patel ${ }^{1, *}$ and Gaurang Shah ${ }^{2, *}$ \\ ${ }^{1}$ Department of Pharmacology and Pharmacy Practice, K. B. Institute of Pharmaceutical Education and Research, \\ Gandhinagar, Gujarat, India and 'Department of Pharmacology, L. M. College of Pharmacy, Ahmedabad, \\ Gujarat, India
}

Correspondence should be addressed R Patel: roshnidutta174@yahoo.co.in

*(R Patel and G Shah contributed equally to this work)

\begin{abstract}
Polycystic ovary syndrome (PCOS) is associated with hyperandrogenism, oligo-anovulation, polycystic ovaries and metabolic syndrome. Many researchers reported that PCOS often starts with menarche in adolescents. Presently available animal model focuses on ovarian but not metabolic features of PCOS. Therefore, we hypothesized that high-fat diet feeding to pre-pubertal female rats results in both reproductive and metabolic features of PCOS. Pre-pubertal female rats were divided into two groups: group I received normal pellet diet and group II received high-fat diet (HFD). In the letrozole study, adult female rats were divided into two groups: group I received $1 \%$ carboxy methyl cellulose and group II received $1 \mathrm{mg} / \mathrm{kg}$ letrozole orally. Oral glucose tolerance test, lipid profile, fasting glucose, insulin, estrus cycle, hormonal profile, ovary weight, luteinizing hormone (LH) receptor and follicle-stimulating hormone receptor expression were measured. Polycystic ovarian morphology was assessed through histopathological changes of ovary. Feeding of HFD gradually increase glucose intolerance and fasting insulin levels. Triglyceride level was higher in HFD study while total cholesterol level was higher in the letrozole study. Alteration in testosterone and estrogen levels was observed in both studies. LH receptor expression was upregulated only in HFD study. Histopathological changes like increase cystic follicle, diminished granulosa cell layer and thickened theca cell layer were observed in letrozole as well as HFD study. High-fat diet initiated at pre-puberty age in rats produces both metabolic disturbances and ovarian changes similar to that observed clinically in PCOS patients. Letrozole on the other hand induces change in ovarian structure and function.

Reproduction (2018) 155 139-149
\end{abstract}

\section{Introduction}

Polycystic ovary syndrome (PCOS) is the most common endocrine disorder encountered in premenopausal women, with estimated prevalence of about 5-10\% (Diamanti-Kandarakis 2008). The symptoms of PCOS were first described by Stein and Levanthal in 1935 (Stein \& Leventhal 1935). It is characterized by clinical or biochemical hyperandrogenism, oligoanovulation and polycystic ovarian morphology (Franks 1995, Azziz et al. 2009). Along with this, metabolic abnormalities such as hyperinsulinemia, impaired glucose tolerance and resulting type II diabetes mellitus (Ehrmann et al. 1999, Park et al. 2001), obesity, dyslipidemia (Moran et al. 2010) and cardiometabolic syndrome (Hoffman \& Ehrmann 2008) are quite frequently observed in PCOS patients.

Currently, three different criteria for diagnosis of PCOS exist. According to Androgen excess-PCOS society 2006, essential components for diagnosis of PCOS are hyperandrogenism along with chronic anovulation or polycystic ovaries (Azziz et al. 2006). In contrast, Rotterdam criteria 2003 suggests the presence of any two of hyperandrogenism, chronic anovulation and polycystic ovaries (No authors listed 2004). Earlier criteria provided by The National Institute of Child Health and Human Development conference, 1990, include only hyperandrogenism and chronic anovulation (Zawadski \& Dunaif 1992).

Since the 1960s, a range of animal models including rodents, sheep and non-human primates have been developed. The prenatal exposure of androgen to sheep and rhesus monkey shows striking similarities with human PCOS (Abbott et al. 1998, Recabarren et al. 2005). However, long developmental line (menarche occurs at 2.5 years of age) and high cost limits the practical utility of these large animal models. On the other hand, rodent models are inexpensive, easy to handle, have short estrous cycles and generation times. Androgens (Pinilla et al. 1993, Wu et al. 2010), estrogens (Brawer et al. 1986, Pinilla et al. 1993) anti-progesterone (Sanchez-Criado et al. 1993) and letrozole (Kafali et al. 2004) are used 
to induce reproductive and metabolic characteristics of PCOS in rats. However, cyclicity and ovarian functions are inconsistently affected in prenatal androgenized animals (Walters et al. 2012). In contrast to enlarged ovaries observed in PCOS patients, postnatal treatment with most androgens show inconsistent increase in luteinizing hormone (LH) and androgen levels and also decreased ovary weight (Walters et al. 2012). Estradiol administration develops cystic follicles, but in most cases, without testosterone overproduction (Paixao et al. 2017). Letrozole, an aromatase inhibitor, frequently used to induce PCOS, produces endogenous hyperandrogenism, disrupts estrous cycle and increases ovarian weight with multiple cysts (Kafali et al. 2004). Producing hormonal imbalances using letrozole develops only ovarian features of PCOS but not the metabolic features (Mannerås et al. 2007). In rodent models, induced hyperandrogenism and resulting imbalanced hormonal milieu leads to development of PCOS. Many studies have determined both the reproductive and metabolic features in hyperandrogenized rodents. The presence of metabolic disturbances in such animals seems to be dependent on the androgen used and also the timing of the treatment.

The prevalence of IR in PCOS patients ranges from 50 to $70 \%$ (Dunaif 1997, Park et al. 2001, Carmina \& Lobo 2004) and occurs independently of obesity (Dunaif et al. 1989). The effect of obesity can aggravate insulin resistance (Dunaif et al. 1989). High insulin levels increase androgen production by augmenting $\mathrm{LH}$ secretion from the pituitary gland, acting synergistically with $\mathrm{LH}$ on thecal cells and reducing hepatic synthesis of serum sex hormone-binding globulin (Nestler et al. 1991, Balen 2004, Sheehan 2004). Insulin exposure to cultured rat anterior pituitary cells cause dose-dependent increase in basal and gonadotropin-releasing hormonestimulated LH and follicle-stimulating hormone release(Adashi et al. 1981, Soldani et al. 1994, 1995). Long-term hyperinsulinemia and IR leads to an increase in serum total and free testosterone levels (Adashi et al. 1981, Declue et al. 1991). Feeding of high-fat diet (HFD) for 120-180 days to an adult rats produce IR, hyperinsulinemia, increased serum progesterone levels, extended estrus cycle and altered ovarian morphology in rats. Moreover, the increase in progesterone levels occur together with enhancement of LH levels (Akamine et al. 2010). Pre-pubertal administration of andronate in HFD-fed rats showed ovarian as well as metabolic features of PCOS such as reduced insulin sensitivity, hyperandrogenism, irregular cycle and increased LH levels (Zhai et al. 2012). Similarly, administration of dehydroepiandrosterone in HFD-fed C57BL/6 prepubertal mice also induces ovarian as well as metabolic features of PCOS (Lai et al. 2014). A significant increase in $\mathrm{LH}$ along with infertility by either $\mathrm{GnRH}$ or insulin stimulation was observed in diet-induced obese wildtype female mice (Brothers et al. 2010). Considering the controversy regarding fundamental pathophysiologic defect of PCOS and parallel growing consensus that development of insulin resistance precedes androgen excess and abnormal gonadotropin dynamics (Guzick \& York 1998), it is worthwhile to study the effect of HFD to pre-pubertal rats. Such study can throw light on possible role of insulin resistance on the development of PCOS. Along with this, pre-pubertal administration of letrozole for 90 days and post-pubertal administration of letrozole for 21 days have shown similarity in generation of PCOS-related ovarian dysfunction and hyperandrogenism. However, insulin resistance was not observed in both cases.

In the present study, we observed the effect of HFD to pre-pubertal rats on ovarian functions, insulin sensitivity and hormonal levels and compared the same with letrozole-induced PCOS in rats. The results of the study can suggest possible use of pre-pubertal HFD as alternative animal models of PCOS.

\section{Materials and methods}

\section{Materials}

The normal pellet diet (NPD) was purchased from VRK Nutritional solutions, Pune, India. The other feed ingredients such as whey protein (Balaji Nutraceuticals, Ahmedabad, India) and choline bitartrate (Chemdyes Corporation, Rajkot, India; Cat. No. CH0171) were procured from commercial sources. Letrozole was purchased from West-coast pharmaceutical works Ltd., Ahmedabad, India.

\section{Animals}

The animals were housed in standard polypropylene cages (three rats/cage) and maintained under controlled room temperature $\left(22 \pm 2^{\circ} \mathrm{C}\right)$ and humidity $(55 \pm 5 \%)$ with $12: 12-\mathrm{h}$ light and darkness cycle. All the rats were provided with commercially available rat NPD and water ad libitum, prior to the dietary manipulation. All experimental protocols (KBIPER/14/481 and KBIPER/16/574) were approved by the Institutional (K. B. Institute of Pharmaceutical Education and Research) Animal Ethics Committee (IAEC) under the Committee for the Purpose of Control and Supervision of Experiments on Animals (CPCSEA) guideline before carrying out the project.

\section{High-fat diet study protocol}

Female Sprague-Dawley rats (3-4 weeks of age, weighing $45-55 \mathrm{~g}$ at the beginning of the experiments) were randomized into two matching weight groups. Rats are allocated into two dietary regimens, Group I $(n=9)$ : control group (NPD: $65 \%$ carbohydrate, $21.5 \%$ protein and $4 \%$ fat and $9.5 \%$ other; $314 \mathrm{kcal})$ and Group II $(n=15)$ : HFD group (HFD: 36\% carbohydrate, 20\% protein, $40 \%$ fat and $4 \%$ other; $530 \mathrm{kcal}$ ) for 105 days. The composition of HFD is given in Table 1. For adapting the animals to HFD $(40 \%)$, the fat content was gradually increased over 2 weeks 
Table 1 Composition of the high-fat diet.

\begin{tabular}{lc}
\hline Ingredients & Percentage $(\%)$ \\
\hline Normal pellet diet & 55.8 \\
Whey protein & 6 \\
Soyabean oil & 19 \\
Coconut oil & 19 \\
Choline bitartrate & 0.2 \\
\hline
\end{tabular}

from $20 \%$ to $40 \%$. Later, the animals were maintained on $40 \%$ HFD throughout the study. Diet was freshly prepared every $3-4$ days and stored at $2-8^{\circ} \mathrm{C}$ till used. Oral glucose tolerance test (OGTT), blood samples for lipid profile and insulin was collected in overnight fasted rats on day 49, 77 and 105. However, blood samples for hormone estimation were collected during diestrus phase.

\section{Letrozole protocol}

Female SD rats (8-10 weeks of age, weighing 200-250g at the beginning of the experiment) were randomized into two groups. Rats displaying normal estrus cycle were selected for study. Group I $(n=9)$ : Control group ( $1 \% \mathrm{CMC})$ and Group II $(n=12)$ : Letrozole group (letrozole $1 \mathrm{mg} / \mathrm{kg}$, p.o. in $1 \% \mathrm{CMC}$ ) for 21 days. The letrozole dose was selected based on the previous study (Kafali et al. 2004). OGTT, blood sample for lipid profile and insulin were collected in overnight fasted rats on day 21. However, blood samples for hormone estimation were collected during diestrus phase.

\section{Oral glucose tolerance test (OGTT) and insulin sensitivity indices}

After an overnight fast, rats were given a glucose load $(2 \mathrm{~g} / \mathrm{kg}$ ) by oral gavage. Blood glucose was estimated using a glucometer (Dr Morepen Glucometer, Delhi, India) at 0, 30, 60 and $120 \mathrm{~min}$. after glucose administration.

The homeostasis model assessment of insulin resistance (HOMA-IR) and $\beta$-cell function (HOMA- $\beta$ ) were calculated using the equations, $\mathrm{HOMA}-\mathrm{IR}=\mathrm{FI} \times \mathrm{FG} / 22.4$ and $\mathrm{HOMA}-\beta=\mathrm{FI} \times 20 /(\mathrm{FG}-3.5)$, where $\mathrm{FI}$ is fasting insulin (in $\mu \mathrm{U} / \mathrm{mL}$ ) and $\mathrm{FG}$ is fasting glucose (in $\mathrm{mmol} / \mathrm{L}$ ). Quantitative insulin sensitivity check index (QUICKI) was calculated as the inverse log sum of fasting insulin (in $\mu \mathrm{U} / \mathrm{mL}$ ) and fasting glucose (in $\mathrm{mg} / \mathrm{dL}$ ) using the equation, $\mathrm{QUICKI}=1 /(\log (\mathrm{FG})+\log (\mathrm{FI})$. Finally, fasting glucoseto-insulin (GI) ratio was calculated as the ratio of $\mathrm{FG}$ (in $\mathrm{mg} / \mathrm{dL}$ ) to $\mathrm{FI}$ (in $\mu \mathrm{U} / \mathrm{mL}$ ).

\section{Determination of estrus cycle}

A vaginal smear was performed 8 days before the day of blood collection. Cells on vaginal walls were collected by washing vagina with normal saline $(0.9 \% \mathrm{NaCl})$ and smeared on glass slides. The slides were examined under microscope for the relative abundance of nucleated epithelial cell (E), cornified epithelial cell (CE) and leucocytes (L). The four stages of cycle estrus (CE), meta-estrus ( $L \& C E)$, diestrus $(L \& E)$ and proestrus (E) were determined.

\section{Biochemical analysis}

Blood was collected from retro-orbital plexus of the rats under light ether anesthesia into Eppendorf tubes. The blood samples were kept at room temperature for $45 \mathrm{~min}$. The serum was separated by centrifugation at $12000 \mathrm{~g}$ for $10 \mathrm{~min}$ at $4{ }^{\circ} \mathrm{C}$ (REMI, Mumbai, India). The serum was analyzed for triglyceride (TG) level (GPO-PAP) and total cholesterol (TC) level (CHOD-POD) using commercially available colorimetric diagnostic kits (Span Diagnostic, Surat, India). Serum insulin, LH, FSH, estrogen, progesterone and testosterone levels were estimated by ELISA kits (Genxbio Health Sciences, Delhi, India).

\section{Ovarian gene expression analysis}

At the end of experiment, ovaries were collected from all groups during diestrus phase and homogenized in RiboExTM (GeneAll Biotechnology, Seoul, South Korea). Total cellular RNA was extracted from ovary using RNA isolation kit (GeneAll biotechnology) in accordance with the manufacturer's instructions. Total RNA from each sample was reverse transcribed into cDNA using PrimeScript Reverse Transcriptase. An equal amount of cDNA from each sample was taken for quantitative real-time PCR using MX3005P qPCR system (Agilent Technologies). Oligonucleotide primers (FP: forward primer; RP: reverse primer) used for qRT-PCR are listed below.

$$
\begin{gathered}
\text { LH receptor - FP: }\left(5^{\prime}-3^{\prime}\right) \text { TCCGTGGACTCCCAAACA, } \\
\text { RP: ATCGTG GCGATCAGCGTA; } \\
\text { FSH receptor - FP: (5'-3') ACTGTGCATTCAACGGAA, } \\
\text { RP: GCCTCC ATGAGGGTGACA; } \\
\begin{array}{c}
\text {-actin - FP: }\left(5^{\prime}-3^{\prime}\right) \text { CTGGAGAAGAGCTATGAGCTGCCTG, } \\
\text { RP: AGGAAGGAAGGCTGGAAGAGAGCCT }
\end{array}
\end{gathered}
$$

Differences in gene expression, expressed as fold-change, were calculated, where $\beta$-actin was used as the reference gene (Livak \& Schmittgen 2001).

\section{Ovarian weight and histopathology of ovary}

At the end of the study, during diestrus phase, rats were killed and ovaries were isolated. Afterward, ovaries were weighted and transferred to $10 \%$ formalin (formaldehyde in saline). Formalin-fixed ovarian tissue was dehydrated, embedded in paraffin and sectioned at $4-5 \mu \mathrm{m}$. Sections were mounted on glass slide and stained with hematoxylin-eosin for light microscopy. The slides were scanned with trinocular microscope Primostar (Zeiss, Germany) and analyzed with Magnus Pro 3.0. The number of follicles, diameter of largest follicle and thickness of follicular wall were measured by two persons blinded to the origin of sections.

\section{Statistical analysis}

Statistical analysis was performed using GraphPad Prism 5 software. Statistical difference between two groups was tested by unpaired $t$-test, and $P<0.05$ was considered significant. Only the effect of letrozole or HFD on body weight and 
glucose level during OGTT were assessed by two-way ANOVA and Bonferroni's post hoc test. All data were expressed as mean \pm S.E.M.

\section{Results}

\section{Body weight and food intake}

The body weight is represented in Fig. 1A and B. Twenty one days after the letrozole administration, significant increase in the body weight was observed in LET group as compared to $\mathrm{CL}$ group (CL: $252 \pm 5.03 \mathrm{~g}$ vs LET: $295 \pm 4.00 \mathrm{~g}, P<0.05)$. However, the feeding of HFD for 105 days did not significantly increase body weight in HFD group as compared to $\mathrm{CH}$ group $(\mathrm{CH} 3: 235 \pm 7.63 \mathrm{~g}$ vs HFD3: $241 \pm 2.46 \mathrm{~g}, P<0.05)$. Feeding of HFD reduces the food intake in HFD group as compared to control group (CL3: $12.69 \pm 0.95 \mathrm{~g} /$ day/animal vs HFD3: $9.01 \pm 1.12 \mathrm{~g} /$ day/animal). Contrary to this, letrozole administration increases food intake in letrozole group as compared to control group (CL: $15.56 \pm 0.67 \mathrm{~g} /$ day/ animal vs LET: $18.11 \pm 0.88 \mathrm{~g} /$ day $/$ animal).

\section{Fasting glucose level, oral glucose tolerance test (OGTT) and area under curve (AUC)}

In the letrozole study, significant difference was observed regarding 2-h glycemia (CL: $127 \pm 7.3$ vs LET:
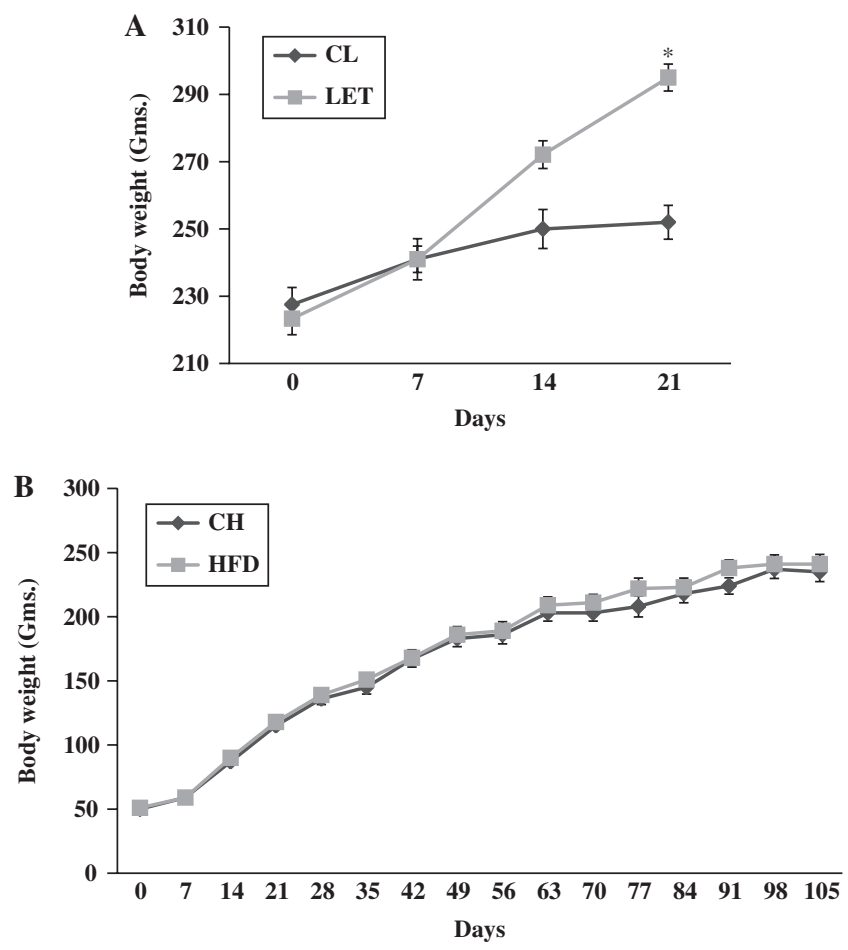

Figure 1 Body weight of animals in the letrozole study (1A) and HFD study (1B); Data represented as mean \pm S.E.M.; ${ }^{*} P<0.05$ compared to control group (unpaired $t$-test); (A) CL-control group; LET-Letrozole group. (B) $\mathrm{CH}$-control group; HFD-High-fat diet group.
$171 \pm 17.48, P<0.05)$ and AUC of OGTT $(\mathrm{CL}: 322 \pm 3.50$ vs LET: $347 \pm 4.10, P<0.05)$. In HFD study, there was no significant change in 2-h glycemia $(\mathrm{CH} 1: 137 \pm 5.09$ vs HFD1: $144 \pm 3.12)$ and AUC of OGTT (CH1: $336 \pm 5.32$ vs HFD1: $318 \pm 5.65)$ between groups on day 49 . Additionally, on day 77, significant change was observed in 2-h glycemia $(\mathrm{CH} 2: 127 \pm 3.92$ vs HFD2: $157 \pm 3.82$, $P<0.05)$ and AUC of OGTT $(\mathrm{CH} 2: 300 \pm 10.33$ vs HFD2: $333 \pm 6.79, P<0.05)$ in HFD2 group as compared to $\mathrm{CH} 2$ group. On day 105 , significant change was observed in
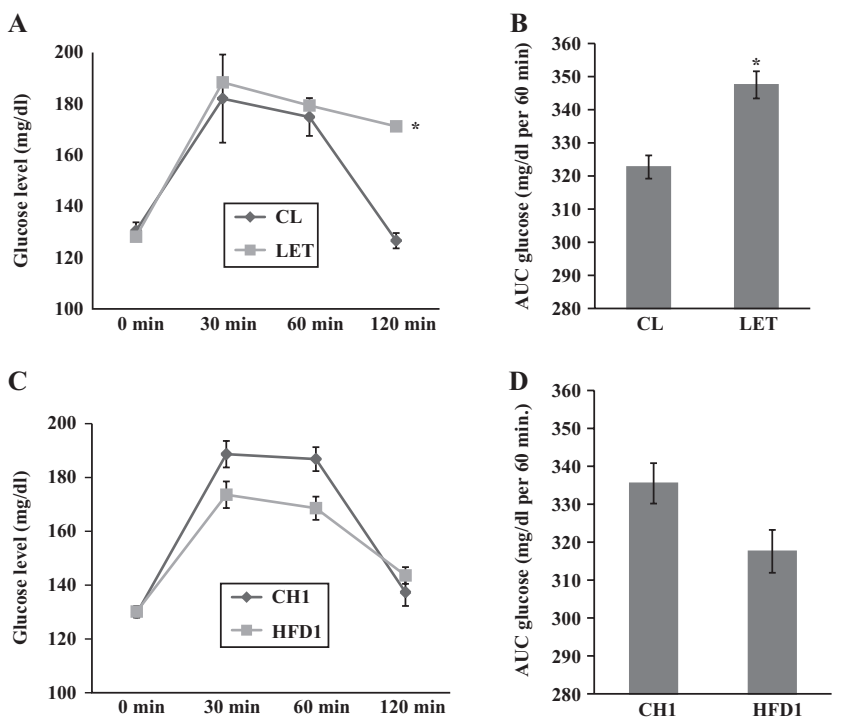

$\mathbf{E}$
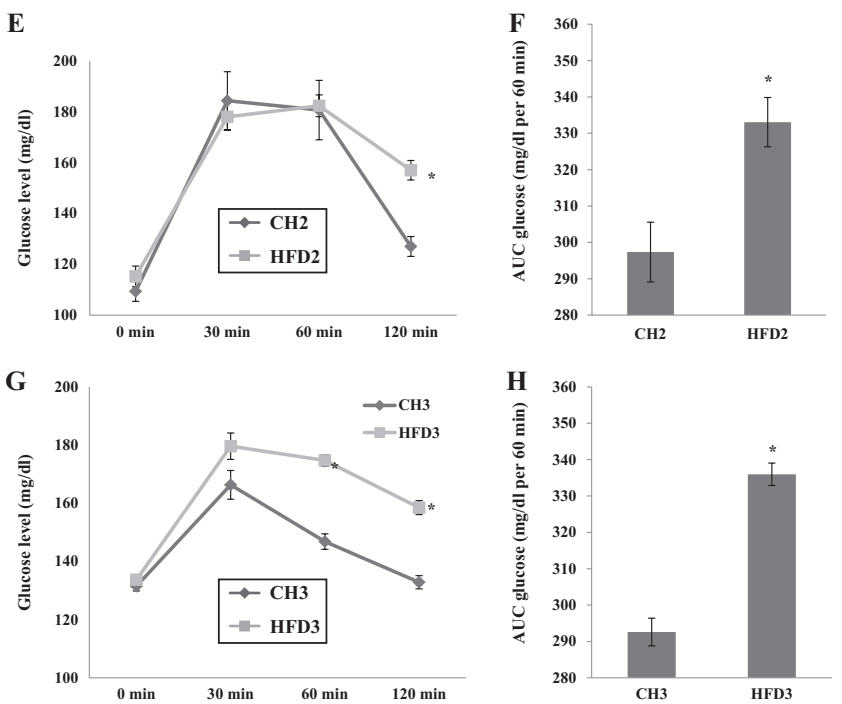

Figure 2 Oral glucose tolerance test and Area under curve of letrozole study (A and B), HFD study on day 49 (C and D) HFD study on day 77 (E and F) and HFD study on day 105 (G and H); Data represented as mean \pm S.E.M.; $* P<0.05$ compared to control group (data of OGTT was analyzed by two-way ANOVA and Bonferroni's post hoc test and data of AUC was analyzed by unpaired $t$-test); $\mathrm{CL}$-control group; LET-Letrozole group. $\mathrm{CH} 1$-control group on day 49; HFD1-HFD group on day 49; $\mathrm{CH} 2$-control group on day 77 ; HFD2-HFD group on day 77 ; $\mathrm{CH} 3$-control group on day 105 ; HFD3-HFD group on day 105. 
Table 2 Fasting glucose level, fasting insulin level and insulin sensitivity indices of different animal groups in the letrozole study and HFD study.

\begin{tabular}{|c|c|c|c|c|c|c|c|}
\hline Groups & $\begin{array}{l}\text { Day of } \\
\text { measurement }\end{array}$ & $\begin{array}{l}\text { Fasting glucose } \\
(\mathrm{mg} / \mathrm{dL})\end{array}$ & $\begin{array}{l}\text { Fasting insulin } \\
(\mathrm{mU} / \mathrm{L})\end{array}$ & HOMA-IR & НОМА- $\beta$ & QUICKI & GI ratio \\
\hline \multicolumn{8}{|c|}{ Letrozole study } \\
\hline $\mathrm{CL}$ & Day 21 & $130.5 \pm 3.25$ & $2.49 \pm 0.55$ & $0.86 \pm 0.1$ & $11.68 \pm 1.68$ & $0.4 \pm 0.007$ & $56.44 \pm 6.44$ \\
\hline LET & Day 21 & $128.17 \pm 6.14$ & $4.65 \pm 0.88$ & $1.58 \pm 0.14$ & $17.88 \pm 1.03$ & $0.36 \pm 0.005$ & $29.12 \pm 3.10$ \\
\hline \multicolumn{8}{|c|}{ HFD study } \\
\hline $\mathrm{CH} 1$ & Day 49 & $129.5 \pm 1.52$ & $1.99 \pm 0.22$ & $0.69 \pm 0.05$ & $9.27 \pm 0.41$ & $0.42 \pm 0.005$ & $66.22 \pm 3.29$ \\
\hline HFD1 & Day 49 & $130.17 \pm 2.08$ & $3.12 \pm 0.06$ & $1.11 \pm 0.03$ & $13.92 \pm 0.68$ & $0.38 \pm 0.001$ & $42.94 \pm 1.15$ \\
\hline $\mathrm{CH} 2$ & Day 77 & $109.33 \pm 3.89$ & $2.05 \pm 0.37$ & $0.58 \pm 0.04$ & $13.41 \pm 1.44$ & $0.43 \pm 0.050$ & $56.15 \pm 4.02$ \\
\hline HFD2 & Day 77 & $115.25 \pm 4.04$ & $10.41 \pm 0.93 *$ & $3.27 \pm 0.27^{*}$ & $61.09 \pm 5.49 *$ & $0.32 \pm 0.004^{*}$ & $11.34 \pm 0.57^{*}$ \\
\hline $\mathrm{CH} 3$ & Day 105 & $131.5 \pm 1.66$ & $1.87 \pm 0.89$ & $0.7 \pm 0.04$ & $9.06 \pm 0.6$ & $0.41 \pm 0.005$ & $67.39 \pm 3.84$ \\
\hline HFD3 & Day 105 & $133.71 \pm 3.31$ & $12.14 \pm 1.44^{*}$ & $4.41 \pm 0.38^{*}$ & $53.08 \pm 3.13 *$ & $0.31 \pm 0.005^{*}$ & $11.35 \pm 0.7^{*}$ \\
\hline
\end{tabular}

Data are represented as mean \pm S.E.M.; ${ }^{*} P<0.05$ compared to respective control group (unpaired $t$-test); In the letrozole study: $\mathrm{CL}$, control group; LET, Letrozole group. In HFD study: CH1, control group on day 49; HFD1, HFD group on day 49; $\mathrm{CH}$ 2, control group on day 77; HFD2, HFD group on day 77; CH3, control group on day 105; HFD3, HFD group on day 105.

2-h glycemia $(\mathrm{CH} 3: 133 \pm 2.27$ vs HFD3: $159 \pm 2.41$ $P<0.05)$ and AUC of OGTT $(\mathrm{CH} 3: 292 \pm 3.81$ vs HFD3: $335.97 \pm 3.08, P<0.05)$ and in HFD3 group as compared to $\mathrm{CH} 3$ group (Fig. 2). The significant change was not observed in fasting glucose level in both studies at any time point (Table 2).

\section{Fasting insulin level and insulin sensitivity indices}

In the letrozole study, there was no significant change in fasting insulin level, HOMA-IR, HOMA- $\beta$, QUICKI and GI ratio. In HFD study, on day 49, there was no significant change in fasting insulin levels and insulin sensitivity indices. However, feeding of HFD leads to significant change in fasting insulin level, HOMA-IR, HOMA- $\beta$, QUICKI and GI ratio in HFD2 and HFD3 groups as compared to respective control group on day 77 and day 105. (Table 2).

Table 3 Lipid profile of different animal group in the letrozole study and HFD study.

\begin{tabular}{llcc}
\hline Groups & $\begin{array}{l}\text { Day of } \\
\text { measurement }\end{array}$ & TG level $(\mathrm{mg} / \mathrm{dL})$ & TC level $(\mathrm{mg} / \mathrm{dL})$ \\
\hline $\begin{array}{l}\text { Letrozole group } \\
\quad \text { CL }\end{array}$ & & & \\
LET & Day 21 & $97.39 \pm 3.6$ & $94.20 \pm 2.59$ \\
HFD group & Day 21 & $135.22 \pm 7.12^{*}$ & $95.18 \pm 3.69$ \\
CH1 & Day 49 & $86.49 \pm 1.47$ & $92.87 \pm 2.8$ \\
HFD1 & Day 49 & $82.72 \pm 1.97$ & $106.43 \pm 6.08$ \\
CH2 & Day 77 & $97.49 \pm 4.25$ & $99.22 \pm 3.56$ \\
HFD2 & Day 77 & $87.27 \pm 1.47$ & $98.34 \pm 2.78$ \\
CH3 & Day 105 & $95.79 \pm 2.69$ & $98.95 \pm 3.53$ \\
HFD3 & Day 105 & $89.00 \pm 1.28$ & $118.74 \pm 2.36^{*}$ \\
\hline
\end{tabular}

Data are represented as mean \pm S.E.M.; ${ }^{*} P<0.05$ compared to respective control group (unpaired $t$-test); In the letrozole study: $\mathrm{CL}$, control group; LET, Letrozole group. In HFD study: $\mathrm{CH} 1$, control group on day 49; HFD1, HFD group on day 49; $\mathrm{CH} 2$, control group on day 77 ; HFD2, HFD group on day 77; $\mathrm{CH} 3$, control group on day $105 ; \mathrm{HFD} 3$, HFD group on day 105.

\section{Lipid profile}

In the letrozole study, TG level was significantly higher $(39 \%)$ in LET group than observed in control animals. However, TC levels remain unaffected. High-fat diet for 105 days (HFD3) caused a small but statistically significant increase in TC levels, but not TG levels, as compared to control animals (Table 3).

\section{Estrus cycle}

Estrus cycle was assessed by vaginal smears. Control animals of letrozole study as well as HFD study exhibited regular estrous cycle of 4-5 days. Vaginal smear of LET group showed only leucocytes, the dominant cell type of the diestrus phase indicating complete acyclicity. However, HFD groups showed prolonged diestrus phase indicating irregular estrous cycles. As the duration of the study increases, duration of diestrus phase gradually increases in HFD group as compared to $\mathrm{CH}$ group (Table 4).

\section{Hormonal profile}

In the letrozole study, significantly lower estrogen level $(27 \%)$ and higher testosterone level (87\%) was observed in LET group as compared to $\mathrm{CL}$ group. However, progesterone levels were similar in both groups. Animals subjected to HFD showed significantly lower estrogen and progesterone levels and higher testosterone levels as compared to control animals. This effect was independent of days of HFD administration. Furthermore, LH, FSH levels and LH/ FSH ratio were not different in both letrozole and HFD study. Table 5 shows the hormonal profile of different animal groups in the letrozole study and HFD study. 
Table 4 Percentage of diestrus phase of different animal groups in the letrozole study and HFD study.

\begin{tabular}{llc} 
Groups & Day of measurement & Diestrus phase $(\%$ of total) \\
\hline $\begin{array}{l}\text { Letrozole study } \\
\text { CL }\end{array}$ & Day $14-21$ & $45.83 \pm 6.97$ \\
LET & Day $14-21$ & $100 \pm 0.00^{*}$ \\
HFD study & & \\
CH1 & Day $42-49$ & $52.08 \pm 2.08$ \\
HFD1 & Day $42-49$ & $61.46 \pm 3.91$ \\
CH2 & Day 70-77 & $54.17 \pm 2.64$ \\
HFD2 & Day 70-77 & $67.71 \pm 2.41^{*}$ \\
$\mathrm{CH} 3$ & Day 98-105 & $52.08 \pm 3.84$ \\
HFD3 & Day $98-105$ & $70.36 \pm 2.18^{*}$ \\
\hline
\end{tabular}

Data are represented as mean \pm S.E.M.; $* P<0.05$ compared to respective control group (unpaired $t$-test); In the letrozole study: $\mathrm{CL}$, control group; LET, Letrozole group. In HFD study: $\mathrm{CH}$ 1, control group on day 49; HFD1, HFD group on day 49; $\mathrm{CH} 2$, control group on day $77 ; \mathrm{HFD} 2, \mathrm{HFD}$ group on day $77 ; \mathrm{CH} 3$, control group on day 105; HFD3, HFD group on day 105.

\section{Ovarian $m R N A$ expression}

A $2.68 \pm 0.24$-fold increases in mRNA expression of LHR with no effect $(1.07 \pm 0.14)$ on Fshr mRNA expression was observed in HFD-fed rats. However, such change in $\mathrm{Lhr}$ $(1.15 \pm 0.64)$ and Fshr $(0.72 \pm 0.16)$ receptor expression was not observed in letrozole-treated animals.

\section{Ovary weight and histopathology of ovary}

Ovary weights of letrozole-treated animals were significantly higher than those in control group animals (CL: $54.96 \pm 3.16 \mathrm{mg}$ vs LET: $71.94 \pm 5.53 \mathrm{mg}, P<0.05$ ). In contrast, in HFD-fed animals, the ovary weight remained unaffected $(\mathrm{CH} 3: 38.94 \pm 1.65 \mathrm{mg}$ vs HFD3: LET: $48.69 \pm 1.22 \mathrm{mg}$ ).

Multiple ovarian follicles and less numbers of corpus luteum were observed in letrozole-treated and HFDfed rats as compared to few ovarian follicles and large number of corpus luteum in control rats. Follicular diameters were also higher in both test group animals as compared to control animals. However, letrozoletreated animals had greater follicular diameter than HFD-fed rats. Additional changes observed were thin layer of granulosa cells, hyperplasia of theca cells and atresia of follicles. During atresia, ovum degenerates and granulosa cells undergo apoptosis, which are replaced by fibrous material (Figs 3 and 4 and Table 6 ).

\section{Discussion}

Insulin resistance, androgen excess and abnormal gonadotropin dynamics are the key elements in pathophysiologic defect of PCOS. Controversy regarding fundamental element in pathophysiology of PCOS exists (Guzick \& York 1998). However, growing evidences suggesting insulin resistance precedes all others (Geffner et al. 1987, Nestler et al. 1989). Both, hyperandrogenism and hyperinsulinemia are frequently observed in clinical PCOS and the underlying treatment majorly targets hyperinsulinemia and insulin resistance (Azziz et al. 2004). Insulin's co-gonadotropin-like activity modulates ovarian steroidogenesis (Balen 2004). Thus, disrupting insulin signaling in the brain affects both ovulation and body weight regulation.

The animal models used for PCOS involve administration of estrogens, anti-progesterone or androgens (Brawer et al. 1986, Pinilla et al. 1993, Sanchez-Criado et al. 1993, Wu et al. 2010). Even letrozole that produce androgenic effects by inhibiting aromatase enzyme has been used to generate PCOS like features in rats (Kafali et al. 2004). Estrogen valerate but not letrozole administration is reported to produce higher fasting glycemia (Daneasa et al. 2016). Several studies have analyzed both the reproductive and metabolic features of hyperandrogenized rodents. The presence of metabolic phenotype seems dependent on the androgen used and the timing of the treatment. Andronate with HFD in rat and dehydroepiandrosterone with HFD in mice shows both ovarian and metabolic features of PCOS which resulted in polycystic ovaries, obesity, irregular cycles of vaginal smear, increased plasma insulin levels, decreased insulin sensitivity, hyperandrogenism and increased LH concentrations (Zhai et al. 2012, Lai et al. 2014). HFD is known to induce various metabolic changes in animals. We attempted to study the effects of HFD feeding to pre-pubertal animals on both ovarian and metabolic functions. By not administering the

Table 5 Hormonal profile in different animal group in the letrozole study and HFD study.

\begin{tabular}{lrlllll}
\hline Groups & FSH $(\mathrm{mIU} / \mathrm{L})$ & LH $(\mathrm{mIU} / \mathrm{L})$ & LH/FSH ratio & Estrogen $(\mathrm{ng} / \mathrm{L})$ & Progesterone $(\mathrm{ng} / \mathrm{ml})$ & Testosterone level $(\mathrm{mlU} / \mathrm{L})$ \\
\hline Letrozole group & & & & & & \\
$\quad$ CL & $10.26 \pm 0.89$ & $8.13 \pm 0.35$ & $0.80 \pm 0.05$ & $59.44 \pm 6.98$ & $126.84 \pm 5.05$ & $4.67 \pm 0.42^{*}$ \\
$\quad$ LET & $9.48 \pm 0.53$ & $7.56 \pm 0.31$ & $0.80 \pm 0.06$ & $43.39 \pm 0.51^{*}$ & $128.17 \pm 4.96$ & $8.77 \pm 0.36$ \\
HFD group & & & & & & \\
CH2 & $14.92 \pm 0.66$ & $12.12 \pm 0.9$ & $0.82 \pm 0.1$ & $58.56 \pm 3.36$ & $331.45 \pm 5.47$ & $19.40 \pm 0.39$ \\
HFD2 & $12.90 \pm 0.83$ & $10.08 \pm 0.23$ & $0.77 \pm 0.06$ & $39.64 \pm 2.09^{*}$ & $162.18 \pm 33.17 *$ & $20.89 \pm 0.92$ \\
CH3 & $13.25 \pm 0.47$ & $11.67 \pm 0.87$ & $0.81 \pm 0.04$ & $59.22 \pm 4.11$ & $311.46 \pm 23.56$ & $17.85 \pm 0.38$ \\
HFD3 & $14.31 \pm 1.07$ & $13.00 \pm 1.22$ & $0.96 \pm 0.11$ & $43.53 \pm 7.32^{*}$ & $205.09 \pm 13.03^{*}$ & $28.09 \pm 2.26^{*}$ \\
\hline
\end{tabular}

Data are represented as mean \pm S.E.M.; ${ }^{*} P<0.05$ compared to respective control group (unpaired $t$-test); In the letrozole study: $\mathrm{CL}$, control group; LET, Letrozole group. In HFD study: $\mathrm{CH}$ 2, control group on day 77; HFD2, HFD group on day 77; $\mathrm{CH}$, control group on day 105; HFD3, HFD group on day 105. 

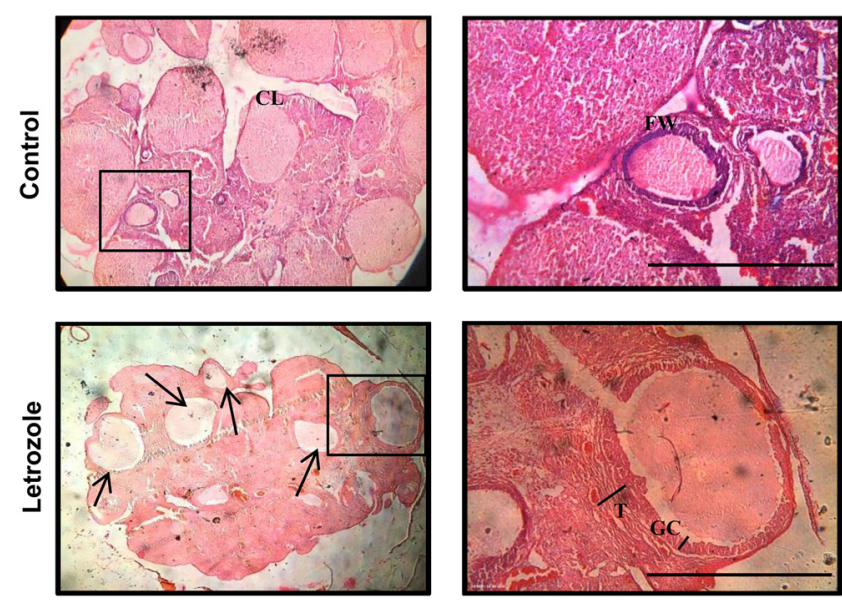

Figure 3 Histological sections of ovaries at different magnification $(10 \times, 100 \times)$ from control rats and letrozole administered rats. Scale bar $1 \mathrm{~mm}$. (-) shows thickness of granulosa cell layer (GC) and Theca layer $(\mathrm{T})$ Control rats: Growing follicles in various stages of development and numerous corpus luteum $(\mathrm{CL})$ are seen. Magnified view demostrates follicle with normal follicular wall (FW) thickness. Letrozole treated rats: Numerous large cyctic follicles (arrows) and least number of corpus luteum are seen. Higher magnification shows increased follicular wall thickness (Granulosa cell layer (GC) and Theca layer $(\mathrm{T})$ ).

androgens, we wished to observe the development of hyperandrogenism by HFD feeding alone.

The HFD fed rats were divided into three subgroups depending on the duration of HFD feeding. Various parameters for detecting, insulin resistance, glucose intolerance, hormonal imbalance and hyperandrogenism were measured in each of these animals. The study
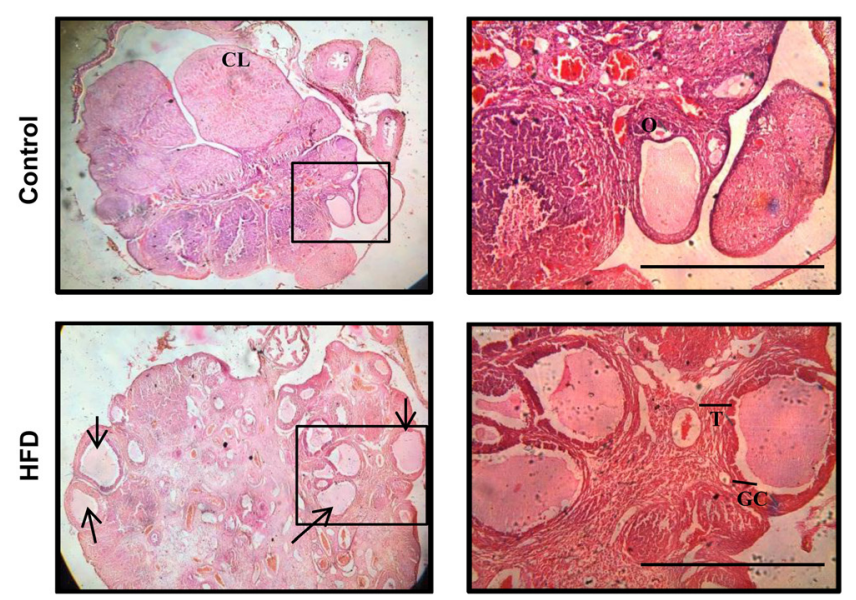

Figure 4 Histological sections of ovaries at different magnification $(10 x, 100 x)$ from control rats and HFD fed rats. Scale bar $1 \mathrm{~mm}$ control rats: Ovary shows follicles at different stages of development and several corpus luteum $(\mathrm{CL})$. Oocyte $(\mathrm{O})$, and normal follicular wall thickness are visible upon magnification. HFD fed rats: Multiple follicles (arrows) are seen. Arrows show follicles in the early process of atresia with apoptotic granulosa cells. Follicles have thickened follicular wall. design helped us to observe time-dependent changes happening in the rats and different stages of disease progression. A separate group of adult rats were administered letrozole to act as positive control.

Since HFD was introduced at pre-pubertal age and letrozole group were introduced in to the study in adult age, the comparison between both the groups is difficult. However, the age of the animals when the final parameters were measured was similar in both study.

Various pilot studies were conducted for optimization of HFD in pre-pubertal rats. In initial pilot study, HFD was prepared simply by addition of fat in normal pellet diet. Nonetheless, addition of high fat replaces the percentage of protein, an important nutrient for the growth of prepubertal rats. Thereafter, protein supplements were added to compensate the need of protein and HFD was prepared with 20,30 and $40 \%$ of fat. On the basis of the results of glucose intolerance and hyperinsulinemia, $40 \%$ HFD was selected for further study (results not shown here). However, to accustom the animals with such high fat, we gradually increased the fat content in the diet over two weeks from 20 to $40 \%$ level.

Twenty-one-day letrozole administration resulted in approximately $30 \%$ increase in body weight in contrast to just $10 \%$ increase in control animals. This is in accordance with reports of previous studies (Mannerås et al. 2007, Maharjan et al. 2010). Lai and coworkers reported that the body weight was increased in DHEA +HFD-treated C57BL/6 mice (Lai et al. 2014). In our study, HFD-fed animals failed to show such rise in body weight. Ramirez and coworkers hypothesized that HFD promotes hyperphagia in rodents (Ramirez 1990). In contrast, we observed approximately $25 \%$ reduction in food intake in HFD-fed rats. In terms of calorie intake, both the normal and high-fat diet-fed animals showed similarity. Chen and coworkers and Picchi and coworkers also reported reduced food intake in HFDfed rats (Chen et al. 2008, Picchi et al. 2011). In clinical situation too, obesity and hyperphagia are not observed in more than $50 \%$ of the PCOS patients (Yen 1980, Franks 1989, Morales et al. 1996).

It is well-known that hyperinsulinemic IR and glucose intolerance plays a prominent role in PCOS. Reduction of insulin sensitivity by $50 \%$ in non-obese PCOS patients and still further reduction in obese PCOS patients well-known (Morales et al. 1996, Holte et al. 2014). This suggest that obesity contributes an additional component to IR (Angioni et al. 2008). Though, elevated fasting insulin level is representing the insulin resistance, simple insulin sensitivity indices like HOMA-IR (ratio indicating insulin resistance), HOMA- $\beta$ (ratio indicating the insulin-secretary capacity of islet $\beta$-cells), QUICKI (log transform of the insulin glucose product) and FGIR are also used to assess insulin sensitivity. FGIR is a useful measure of insulin sensitivity in women with PCOS (Legro et al. 1998). Furthermore, glucose intolerance also can be better evaluated by OGTT rather than alone 
Table 6 Histopathological changes of ovary in the letrozole study and in HFD study.

\begin{tabular}{lcccc}
\hline & CL $(n=9)$ & LET $(n=10)$ & CH $(n=9)$ & HFD $(n=12)$ \\
\hline Number of follicles $(n)$ & $2.12 \pm 0.03$ & $7.89 \pm 0.06^{*}$ & $1.54 \pm 0.07$ & $9.34 \pm 0.13^{*}$ \\
Number of corpus lutea $(n)$ & $10.26 \pm 0.04$ & $4.05 \pm 0.05^{*}$ & $10.78 \pm 0.04$ & $7.22 \pm 0.03^{*}$ \\
Diameter of largest follicle $(\mu \mathrm{m})$ & $268.65 \pm 33.1$ & $867.32 \pm 34.78^{*}$ & $233.65 \pm 29.12$ & $478.32 \pm 21.22^{*}$ \\
Thickness of follicular wall $(\mu \mathrm{m})$ & $58.34 \pm 2.67$ & $158.34 \pm 7.43^{*}$ & $71.45 \pm 1.97$ & $145.23 \pm 10.23^{*}$ \\
\hline
\end{tabular}

Data are represented as mean \pm S.E.M.; $* P<0.05$ compared to control group (unpaired $t$-test).

$\mathrm{CH}$, control group for HFD group; $\mathrm{CL}$, control group for LET; HFD, high-fat diet group; LET-Letrozole group.

fasting glucose level in PCOS patients (Legro et al. 1998, Mastuda \& Defronzo 1999). Except for the glucose intolerance reflected in OGTT test, no other parameters which can reflect IR showed any changes due to letrozole administration. Similar observations have been reported in earlier studies (Mannerås et al. 2007, Maharjan et al. 2010, Reddy et al. 2016). Feeding of HFD for 120 days to an adult female rats produced IR and ovulatory infertility (Akamine et al. 2010). Impaired glucose tolerance and IR was also observed in DHEA + HFD treated C57BL/6 mice (Lai et al. 2014). Similarly, we also observed a gradual increase in fasting insulin levels and glucose intolerance after 49 days of HFD feeding which became more prominent with further continuation of HFD. This suggests that after 49 days of HFD feeding, metabolic disturbances becomes observable. The development of insulin resistance and increased glucose intolerance in HFD fed animals was not associated with increase in body weight. A more detailed study which can look in to the changes in liver and adipose tissue may help in understanding the possible cause of insulin resistance without developing obesity.

According to the National Cholesterol Education Program (NCEP) guidelines, approximately $70 \%$ of PCOS women exhibit abnormal serum lipid levels. As PCOS women are also insulin resistant, it would be expected that IR is responsible for reduction in the activity of lipoprotein lipase and resulting dyslipidemia (De Fronzo \& Ferraninni 1991, Krauss \& Siri 2004). HFD gradually increased TC level but not TG level. Increased TC level was also reported in DHEA + HFD treated C57BL/6 mice (Lai et al. 2014). In letrozole treated rats, TG levels were higher and TC levels remained unaffected. In one study, letrozole caused increase in both TG and TC level (Reddy et al. 2016). The other study, reported no effect on lipid profile (Mannerås et al. 2007).

Letrozole, a non-steroidal aromatase inhibitor reduces conversion of androgens to estrogens in the ovary (Corbin et al. 1999). This is reflected as lower estrogen and higher testosterone levels in letrozole treated rats. Additionally, progesterone levels are also reduced (Kafali et al. 2004, Baravalle et al. 2006, Mannerås et al. 2007). Our observations in letrozole treated animals are also similar. The hormonal changes in HFD fed rats could be as a consequence to insulin resistance and hyperinsulinemia. Insulin mediates hyperandrogenism by decreased hepatic production of SHBG (Nestler et al. 1991), by activation of inositol phosphoglycan pathway in theca cell (Medina \& Nestler 1998) and amplification of LH response on theca cells (Krauss \& Siri 2004).

Pulsatile GnRH stimulation is required to maintain ratio of gonadotropins secretion which is modified by hyperinsulinemia (Dunaif 1997). Along with this, reduction in estrogen level weakens the negative feedback on LH production in pituitary (Ajika et al. 1972). This is reflected by increased LH level, increase/ no change in FSH levels or altered $\mathrm{LH} / \mathrm{FSH}$ ratio $(>2: 1)$ in PCOS patients. Both $\mathrm{LH}$ and FSH levels and their ratio remained unaltered by HFD. However, LH receptor expression got up-regulated by 2.6 folds with little effect on FSH receptor expression. The lack of effect on $\mathrm{LH}$ levels in HFD fed rats could probably be because of serum sampling in the morning which missed the highamplitude LH pulses during night (Venturoli et al. 1988). Though, altered LH/FSH ratio is present in a significant proportion of women with PCOS and is suggestive of PCOS but is not specific for diagnosis (Zawadski \& Dunaif 1992).

The increased hyperinsulinemia increases the expression of $\mathrm{LH}$ receptor, which in turn can lead to potentiation of ovarian steroidogenic response to gonadotropins, prematuregranulosa differentiation, arrest of follicular growth and resulting anovulation (Hegsted et al. 1974, Thiruppathi et al. 2001, Stracquadanio \& Ciotta 2015). The absence of hyperinsulinemia could at least partly explain unaltered LH receptor expression in letrozole-treated rats.

A gradual increase in diestrus phase duration is suggestive of disrupted estrus cycle in HFD fed rats. Letrozole administration also produced complete acyclicity in rats. Thus, fertility is significantly impaired in both cases. Imbalance in sex hormone levels also produced structural changes in ovary. The number of cystic follicles was increased and cystic wall was thickened characterized by attenuated or diminished granulosa cell layer and thickened theca cell layer in letrozole-treated as well as HFD-fed rats. Along with this, the ovary also showed increase in atretic antral follicles and decrease in corpus luteum. These histopathological changes in rat ovaries, resembles with earlier studies (Kafali et al. 2004, Mannerås et al. 2007).

PCOS, as earlier stated, is characterized by hyperandrogenism, polycystic ovaries and oligo and/or anovulation and endocrine disorder with numerous 
metabolic consequences, prominent being insulin resistance (Oakley \& Lin 2011). In the present study, the initiating HFD in pre-pubertal rats and continuing it for 105 days resulted in all of the above mentioned disturbances. However, LH levels remained unaffected in this study. Thus, inducting HFD at early age in rats has special merits over many other available animal models for PCOS.

\section{Conclusion}

HFD initiated at pre-puberty age in rats produces both metabolic disturbances and ovarian changes like increase number of cystic follicles and increase follicular wall thickness similar to that observed clinically in PCOS patients. The developments of these features are slow and progressive and mimics closely to clinical PCOS. Letrozole on the other hand induces change in ovarian structure and function without producing any metabolic disturbances. Also, these changes are quite rapidly developed as compared to those observed with HFD model. As the HFD-induced model produces hyperinsulinaemia-induced hyperandrogenism, it may become helpful in understanding the pathogenesis of PCOS.

\section{Declaration of interest}

The authors declare that there is no conflict of interest that could be perceived as prejudicing the impartiality of the research reported.

\section{Funding}

This work was supported by grant from the Gujarat council on science and technology, under the minor research project scheme (Grant No.: GUJCOST/MRP/2015-16/2689).

\section{References}

Abbott DH, Dumesic DA, Eisner JR, Colman RJ \& Kemnitz JW 1998 Insights into the development of polycystic ovary syndrome (PCOS) from studies of prenatally androgenized female rhesus monkeys. Trends in Endocrinology and Metabolism 9 62-67. (https://doi.org/10.1016/ S1043-2760(98)00019-8)

Adashi EY, Hsueh AJ \& Yen SS 1981 Insulin enhancement of luteinizing hormone and follicle-stimulating hormone release by cultured pituitary cells. Endocrinology 108 1441-1449. (https://doi.org/10.1210/endo108-4-1441)

Ajika K, Krulich L, Fawcett C \& McCann S 1972 Effects of estrogen on plasma and pituitary gonadotropins and prolactin, and on hypothalamic releasing and inhibiting factors. Neuroendocrinology 9 304-315. (https://doi.org/10.1159/000122062)

Akamine EH, Marcal AC, Camporez JP, Hoshida MS, Caperuto LC, Bevilacqua E \& Carvalho CR 2010 Obesity induced by high-fat diet promotes insulin resistance in the ovary. Journal of Endocrinology 206 65-74. (https://doi.org/10.1677/JOE-09-0461)

Angioni S, Portoghese E, Milano F, Melis GB \& Fulghesu AM 2008 Diagnosis of metabolic disorders in women with polycystic ovary syndrome. Obstetrical and Gynecological Survey 63 796-802. (https://doi.org/10.1097/OGX.0b013e3181895a06)
Azziz R, Woods KS, Reyna R, Key TJ, Knochenhauer ES \& Yildiz BO 2004 The prevalence and features of the polycystic ovary syndrome in an unselected population. Journal of Clinical Endocrinology and Metabolism 89 2745-2749. (https://doi.org/10.1210/jc.2003-032046)

Azziz R, Carmina E, Dewailly D, Diamanti-Kandarakis E, EscobarMorreale HF, Futterweit W, Janssen OE, Legro RS, Norman RJ, Taylor AE et al. 2006 Position statement: criteria for defining polycystic ovary syndrome as a predominantly hyperandrogenic syndrome: an androgen excess society guideline. Journal of Clinical Endocrinology and Metabolism 91 4237-4245. (https://doi.org/10.1210/jc.2006-0178)

Azziz R, Carmina E, Dewailly D, Diamanti-Kandarakis E, EscobarMorreale HF, Futterweit W, Janssen OE, Legro RS, Norman RJ, Taylor AE et al. 2009 The androgen excess and PCOS society criteria for the polycystic ovary syndrome: the complete task force report. Fertility and Sterility 91 456-488. (https://doi.org/10.1016/j.fertnstert.2008.06.035)

Balen A 2004 The pathophysiology of polycystic ovary syndrome: trying to understand PCOS and its endocrinology. Best Practice and Research: Clinical Obstetrics and Gynaecology 18 685-706. (https://doi. org/10.1016/j.bpobgyn.2004.05.004)

Baravalle C, Salvetti NR, Mira GA, Pezzone N \& Ortega HH 2006 Microscopic characterization of follicular structures in letrozole-induced polycystic ovarian syndrome in the rat. Archives of Medical Research $\mathbf{3 7}$ 830-839. (https://doi.org/10.1016/j.arcmed.2006.04.006)

Brawer JR, Munoz M \& Farookhi R 1986 Development of the polycystic ovarian condition (PCO) in the estradiol valerate-treated rat. Biology of Reproduction 35 647-655. (https://doi.org/10.1095/ biolreprod35.3.647)

Brothers KJ, Wu S, Divall SA, Messmer MR, Kahn CR, Miller RS, Radovick S, Wondisford FE \& Wolfe A 2010 Rescue of obesity-induced infertility in female mice due to a pituitary-specific knockout of the insulin receptor. Cell Metabolism 12 295-305. (https://doi.org/10.1016/j. cmet.2010.06.010)

Carmina E \& Lobo RA 2004 Use of fasting blood to assess the prevalence of insulin resistance in women with polycystic ovary syndrome. Fertility and Sterility 82 661-665. (https://doi.org/10.1016/j.fertnstert.2004.01.041)

Chen W-P, Ho B-Y, Lee C-L, Lee C-H \& Pan T-M 2008 Red mold rice prevents the development of obesity, dyslipidemia and hyperinsulinemia induced by high-fat diet. International Journal of Obesity 32 1694-1704. (https://doi.org/10.1038/ijo.2008.156)

Corbin CJ, Trant JM, Walters KW \& Conley AJ 1999 Changes in testosterone metabolism associated with the evolution of placental and gonadal isozymes of porcine. Endocrinology 140 5202-5210. (https://doi.org/10.1210/endo.140.11.7140)

Daneasa A, Cucolaş C, Lenghel LM, Olteanu D, Orəsan R \& Filip GA 2016 Letrozole vs estradiol valerate induced PCOS in rats: glycemic, oxidative and inflammatory status assessment. Reproduction 151 401-409. (https://doi.org/10.1530/REP-15-0352)

Declue TJ, Shah SC, Marchese M \& Malone JI 1991 Insulin resistance and hyperinsulinemia induce hyperandrogenism in a young type B insulin resistant female. Journal of Clinical Endocrinology and Metabolism 72 1308-1311. (https://doi.org/10.1210/jcem-72-6-1308)

Diamanti-Kandarakis E 2008 Polycystic ovarian syndrome: pathophysiology, molecular aspects and clinical implications. Expert Reviews in Molecular Medicine 10 e3. (https://doi.org/10.1017/S1462399408000598)

Dunaif A 1997 Insulin resistance and the polycystic ovary syndrome: mechanism and implications for pathogenesis. Endocrine Reviews 18 774-800. (https://doi.org/10.1210/edrv.18.6.0318)

Dunaif A, Segal KR, Futterweit W \& Dobrjansky A 1989 Profound peripheral insulin resistance, independent of obesity, in polycystic ovary syndrome. Diabetes 38 1165-1174. (https://doi.org/10.2337/ diab.38.9.1165)

Ehrmann D, Barnes R, Rosenfield R, Cavaghan M \& Imperial J 1999 P revalence of impaired glucose tolerance and diabetes in women With polycystic ovary syndrome. Diabetes Care 22 141-146. (https://doi. org/10.2337/diacare.22.1.141)

Franks S 1989 Polycystic ovary syndrome: a changing perspective. Clinical Endocrinology 31 87-120. (https://doi.org/10.1111/j.1365-2265.1989. tb00457.x)

Franks S 1995 Polycystic ovary syndrome. New England Journal of Medicine 333 853-861. (https://doi.org/10.1056/NEJM199509283331307)

De Fronzo R \& Ferraninni E 1991 Insulin resistance. A multifaceted syndrome responsable for NIDDM, obesity, hypertension, dyslipemia 
and atherosclerotic cardiovascular disease. Diabetes Care 14 177-185. (https://doi.org/10.2337/diacare.14.3.173)

Geffner ME, Kaplan SA, Bersch N, Golde DW, Landaw EM \& Chang RJ 1987 Persistence of insulin resistance in polycystic ovarian disease after inhibition of ovarian steroid secretion. Obstetrical and Gynecological Survey 42 308-310. (https://doi.org/10.1097/00006254-19870500000014)

Guzick D \& York N 1998 Polycystic ovary syndrome : symptomatology, pathophysiology, and epidemiology. American Journal of Obstetrics and Gynecology 179 89-93. (https://doi.org/10.1016/S00029378(98)70238-8)

Hegsted DM, Gallagher A \& Hanford H 1974 Inositol requirement of the gerbil. Journal of Clinical Endocrinology and Metabolism 104 588-592.

Hoffman LK \& Ehrmann DA 2008 Cardiometabolic features of polycystic ovary syndrome. Nature Clinical Practice: Endocrinology and Metabolism 4 215-222. (https://doi.org/10.1038/ncpendmet0755)

Holte J., Bergh T, Berne C, Wide L \& Lithell H 2014 Restored insulin sensitivity but persistently increased early insulin secretion after weight loss in obese women with polycystic ovary syndrome. Journal of Clinical Endocrinology and Metabolism 80 2586-2593. (https://doi.org/10.1210/ jcem.80.9.7673399)

Kafali H, Iriadam M, Ozardali I \& Demir N 2004 Letrozole-induced polycystic ovaries in the rat: a new model for cystic ovarian disease. Archives of Medical Research 35 103-108. (https://doi.org/10.1016/j. arcmed.2003.10.005)

Krauss RM \& Siri PW 2004 Metabolic abnormalities: triglyceride and lowdensity lipoprotein. Endocrinology and Metabolism Clinics of North America 33 405-415. (https://doi.org/10.1016/j.ecl.2004.03.016)

Lai H, Jia X, Yu Q, Zhang C, Qiao J, Guan Y \& Kang J 2014 High-fat diet induces significant metabolic disorders in a mouse model of polycystic ovary syndrome. Biology of Reproduction 91 1-11. (https://doi.org/10.1095/biolreprod.114.120063)

Legro RS, Finegood D \& Dunaif A 1998 A fasting glucose to insulin ratio is a useful measure of insulin sensitivity in women with polycystic ovary syndrome. Journal of Clinical Endocrinology and Metabolism 83 2694-2698. (https://doi.org/10.1097/00006254-199901000-00019)

Livak KJ \& Schmittgen TD 2001 Analysis of relative gene expression data using real-time quantitative PCR. Methods 25 402-408. (https://doi. org/10.1006/meth.2001.1262)

Maharjan R, Nagar PS \& Nampoothiri L 2010 Effect of Aloe barbadensis Mill. formulation on Letrozole induced polycystic ovarian syndrome rat model. Journal of Ayurveda and Integrative Medicine 1 273-279. (https://doi.org/10.4103/0975-9476.74090)

Mannerås L, Cajander S, Holmäng A, Seleskovic Z, Lystig T, Lönn M \& Stener-Victorin E 2007 A new rat model exhibiting both ovarian and metabolic characteristics of polycystic ovary syndrome. Endocrinology 148 3781-3791. (https;//doi.org/10.1210/en.2007-0168)

Mastuda M \& Defronzo RA 1999 Insulin sensitivity indices obtained from comparison with the euglycemic insulin clamp. Diabetes Care $\mathbf{2 2}$ 1462-1470. (https://doi.org/10.2337/diacare.22.9.1462)

Medina F \& Nestler J 1998 Insulin stimulates testosterone biosynthesis by human theca cells from women with polycystic ovary syndrome by activating its own receptor and using inositoglycan mediators as the signal transduction system. Journal of Clinical Endocrinology and Metabolism 83 2001-2005. (https://doi.org/10.1210/jcem.83.6.4886)

Morales AJ, Laughlin GA, Butzow T, Maheshwari H, Baumann G \& Yen SSC 1996 Insulin, somatotropic, and luteinizing hormone in lean and obese women with polycystic ovary syndrome: common and distinct features. Journal of Clinical Endocrinology and Metabolism $\mathbf{8 1}$ 2854-2864. (https://doi.org/10.1210/jcem.81.8.8768842)

Moran LJ, Misso ML, Wild RA \& Norman RJ 2010 Impaired glucose tolerance, type 2 diabetes and metabolic syndrome in polycystic ovary syndrome: a systematic review and meta-analysis. Human Reproduction Update 16 347-363. (https://doi.org/10.1093/humupd/dmq001)

Nestler JE, Barlascini CO, Matt DW, Steingold KA, Plymate SR, Clore JN \& Blackard WG 1989 Suppression of serum insulin by diazoxide reduces serum testosterone levels in obese women with polycystic ovary syndrome. Journal of Clinical Endocrinology and Metabolism 68 1027-1032. (https://doi.org/10.1210/jcem-68-6-1027)

Nestler JE, Powers LP, Matt DW, Steingold KA, Plymate SR, Rittmaster RR, Clore JN \& Blackard WG 1991 A direct effect of hyperinsulinemia on serum sex hormone-binding globulin levels in obese women with the polycystic ovary syndrome. Journal of Clinical Endocrinology and Metabolism 72 83-89. (https://doi.org/10.1210/jcem-72-1-83)

Revised 2003 consensus on diagnostic criteria and long-term health risks related to polycystic ovary syndrome 2004. Human Reproduction 19 41-47.

Oakley O \& Lin P 2011 Animal models for the study of polycystic ovarian syndrome. Endocrinology and Metabolism 26 193-202. (https://doi. org/10.3803/EnM.2011.26.3.193)

Paixao L, Ramos RB, Lavarda A, Morsh DM \& Spritzer PM 2017 Animal models of hyperandrogenism and ovarian morphology changes as features of polycystic ovary syndrome: a systematic review. Reproductive Biology and Endocrinology 15 12. (https://doi.org/10.1186/s12958-0170231-z)

Park KH, Kim JY, Ahn CW, Song YD, Lim SK \& Lee HC 2001 Polycystic ovarian syndrome (PCOS) and insulin resistance. International Journal of Gynecology and Obstetrics 74 261-267. (https://doi.org/10.1016/ S0020-7292(01)00442-8)

Picchi MGP, de Mattos AM, Barbosa MR, Duarte CP, Gandini Mde A, Portari GV \& Jordão AA 2011 A high-fat diet as a model of fatty liver disease in rats. Acta Cirurgica Brasileira 26 25-30. (https://doi. org/10.1590/S0102-86502011000800006)

Pinilla L, Trimino E, Garnelo P, Bellido C, Aguilar R, Gaytan F \& Aguilar E 1993 Changes in pituitary secretion during the early postnatal period and anovulatory syndrome induced by neonatal oestrogen or androgen in rats. Journal of Reproduction and Fertility 97 13-20. (https://doi. org/10.1530/jrf.0.0970013)

Ramirez I 1990 Does dietary hyperphagia contradict the lipostatic theory? Neuroscience and Biobehavioral Reviews 14 117-123. (https://doi. org/10.1016/S0149-7634(05)80212-X)

Recabarren SE, Padmanabhan V, Codner E, Lobos A, Duran C, Vidal M, Foster DL \& Sir-Petermann T 2005 Postnatal developmental consequences of altered insulin sensitivity in female sheep treated prenatally with testosterone. American Journal of Physiology: Endocrinology and Metabolism 289 E801-E806. (https://doi. org/10.1152/ajpendo.00107.2005)

Reddy PS, Begum N, Mutha S \& Bakshi V 2016 Beneficial effect of Curcumin in Letrozole induced polycystic ovary syndrome. Asian Pacific Journal of Reproduction 5 116-122. (https://doi.org/10.1016/j. apjr.2016.01.006)

Sanchez-Criado JE, Sanchez A, Ruiz A \& Gaytan F 1993 Endocrine and morphological features of cystic ovarian condition in antiprogesterone RU486-treated rats. Acta Endocrinologica 129 237-245.

Sheehan MT 2004 Polycystic ovarian syndrome: diagnosis and management. Clinical Medicine and Research 2 13-27. (https://doi. org/10.3121/cmr.2.1.13)

Soldani R, Cagnacci A \& Yen SS 1994 Insulin, insulin like growth factor I (IGF-I) and IGF-II enhance basal and Gonadotrophin-releasing hormonestimulated luteinizing hormone release from rat anterior pituitary cells in vitro. European Journal of Endocrinology 131 641-645. (https://doi. org/10.1530/eje.0.1310641)

Soldani R, Cagnacci A, Paoletti AM, Yen SS \& Melis GB 1995 Modulation of anterior pituitary luteinizing hormone response to gonadotropin-releasing hormone by insulin-like growth factor I in vitro. Fertility and Sterility 64 634-637. (https://doi.org/10.1016/ S0015-0282(16)57804-2)

Stein IF \& Leventhal ML 1935 Amenorrhea associated with bilateral polycystic ovaries. American Journal of Obstetrics and Gynecology 29 181-191. (https://doi.org/10.1016/S0002-9378(15)30642-6)

Stracquadanio M \& Ciotta L 2015 Metabolic Aspects of PCOS: Treatment With Insulin Sensitizers. Switzerland: Springer International Publishing.

Thiruppathi P, Shatavi S, Dias JA, Radwanska E \& Luborsky JL 2001 Gonadotrophin receptor expression on human granulosa cells of low and normal responders to FSH. Molecular Human Reproduction 7 697-704. (https://doi.org/10.1093/molehr/7.8.697)

Venturoli S, Porcu E, Fabbri R \& Bolzani R 1988 Episodic pulsatile secretion of FSH, LH, prolactin, oestrdiol, oestrone, and LH circadian variation in ploycystic ovary syndrome. Clinical Endocrinology 28 93-107. (https://doi.org/10.1111/j.1365-2265.1988.tb01208.x)

Walters KA, Allan CM \& Handelsman DJ 2012 Rodent models for human polycystic ovary syndrome. Biology of Reproduction 86 1-12. 
Wu XY, Li ZL, Wu CY, Liu YM, Lin H, Wang SH \& Xiao WF 2010 Endocrine traits of polycystic ovary syndrome in prenatally androgenized female Sprague-Dawley rats. Endocrine Journal 57 201-209. (https://doi. org/10.1507/endocrj.K09E-205)

Yen SSC 1980 The polycystic ovary syndrome. Clinical Endocrinology 12 177. (https://doi.org/10.1111/j.1365-2265.1980.tb02132.x)

Zawadski J \& Dunaif A 1992 Diagnostic Criteria for Polycystic Ovary Syndrome: Towards a Rational Approach. Boston: Blackwell Scientific Publications.

Zhai H-L, Wu H, Xu H, Weng P, Xia F-Z, Chen Y \& Lu Y-L 2012 Trace glucose and lipid metabolism in high androgen and high-fat diet induced polycystic ovary syndrome rats. Reproductive Biology and Endocrinology 10 5. (https://doi.org/10.1186/1477-7827-10-5)

Received 23 September 2017

First decision 16 October 2017

Revised manuscript received 30 October 2017

Accepted 9 November 2017 